\title{
Integration of Innovation and Entrepreneurship Ecosystem Elements: The Whole is Greater than the Sum of the Parts
}

\section{Ms. Mary Raber, Michigan Technological University}

Mary Raber currently serves as Assistant Dean for Academic Programs for the Pavlis Honors College, and co-Director of the newly created Innovation Center for Entrepreneurship at Michigan Technological University. Prior to this role, she was responsible for the development and growth of Michigan Tech's innovative Enterprise Program. Within the Pavlis Honors College her responsibilities include curricular development and assessment for experiential learning programs such as the Enterprise and Pavlis Global Technological Leadership programs. She received her BS in Mechanical Engineering from the University of Michigan and MBA from Wayne State University and is currently working on her $\mathrm{PhD}$ at Michigan Technological University. Before joining MTU she held various engineering and management positions during a 15 year career in the automotive industry.

\section{Dr. James R. Baker, Michigan Technological University}

Jim Baker currently serves in a split role as Executive Director of Innovation and Industry Engagement and as Co-Director of the Innovation Center for Entrepreneurship (ICE) within the Pavlis Honors College at Michigan Technological University. In this role he leverages his responsibilities for and experience with; industrial sponsored research contracting, technology transfer, startup business development, corporate relations into a bridge to student entrepreneurship, innovation and experiential education activities. He has taught undergraduate and graduate courses on technology commercialization and intellectual property law, is a licensed Patent Agent, holds a Ph.D. in environmental engineering, and a partner in a Michiganbased manufacturing company. 


\title{
Integration of Innovation and Entrepreneurship Ecosystem Elements - The Whole is Greater than the Sum of the Parts
}

\begin{abstract}
At Michigan Technological University we have carried a long-term goal and expectation for student start-ups and other commercial outcomes from interdisciplinary student-led design programs. Over the years, and through the efforts of a few individuals, we have developed pockets of programs and support resources in an effort to advance this goal and to assist students in following through on their innovation and entrepreneurship interests. While these programs and resources have resulted in some successes, to-date we have largely fallen short of our goals regarding innovative products in the marketplace and new companies founded by students. Within the past two years however, we have experienced a perfect storm of efforts, interests and activities that have now aligned to allow for significant traction in the realization of a cohesive set of resources - what we refer to as an integrated Innovation and Entrepreneurship (I\&E) Ecosystem. The goals of our integrated ecosystem include the creation of cohesive learning environments, programs, and services that better engage students, faculty and staff in a) developing an innovation and entrepreneurial mindset, b) creating a bridge across academic units and the community at-large to foster collaboration, and c) connecting student innovators and entrepreneurs with resource networks that enable outcomes related to startup business execution and market entry for new innovative products.
\end{abstract}

Through this paper we share our grass roots journey to creating an I\&E Ecosystem on our campus, and to provide information on the programs, individuals, and networks that have helped us to move forward along the way. We will also describe our efforts to assess the state of evolution of the broad I\&E Ecosystem over time. Through the efforts of a few champions who have maintained a passion for creating this ecosystem, and as the result of a series of fortunate circumstances, this journey has recently resulted in; a) the creation of an interdisciplinary college with innovation and entrepreneurship as a core element of its mission, b) active participation in transformative programs such as I-Corps, Pathways to Innovation, and University Innovation Fellows, c) the development of new educational offerings and adjustments to existing offerings, and d) support from entrepreneurial alumni. We will share how this decade long journey is generating a cultural change on our campus and discuss the lessons we've learned along the way.

\section{Background}

As noted by leaders of Stanford's Epicenter program, "ongoing innovation is required to address pressing problems and to maintain America's global competitiveness, and it is the responsibility of educators to teach their students to be more innovative and entrepreneurial.",3

Entrepreneurship education teaches students of all disciplines the knowledge, tools and attitudes needed to identify opportunities and bring them to life, and these skills are as relevant for success in established businesses as they are for start-ups. ${ }^{3}$ Furthermore, there is a substantial and growing demand by students for entrepreneurship education and development of an entrepreneurial mindset. In an annual survey of first-year college students in the US, $41 \%$ of respondents indicated that "becoming successful in a business of my own" is an objective they consider "essential" or "very important". 6 
Michigan Tech offers a wealth of experiential learning opportunities to its undergraduate students, from the highly distinctive and interdisciplinary Enterprise program, to Senior Capstone experiences in engineering and entrepreneurship within many individual academic units. All of these programs provide a strong hands-on approach to problem solving, and many of them begin to expose students to the skills that will help them be successful as entrepreneurs leading new companies or as "intrapreneurs" practicing innovation and leadership within established companies. Unfortunately, there has been no clear place or path in our curriculum or within the local resource network where students are deliberately exposed to, and educated in, the process of directed innovation and disciplined evaluation of commercial opportunities. Furthermore, for those students having the motivation and fortitude to try to push their ideas forward, it is unclear to them how, where and even when they can tap in to the available support resources. And while many general support resources exist, there are notable gaps, and even for the existing resources, we lack a reasonably defined and cohesive structure for engaging with those resources. More importantly, there is no underlying support infrastructure to assist students in engaging with the resources that are most appropriate and relevant to them considering their stage of professional and commercial development, nor to help them manage and focus their efforts accordingly. As a result, students most often struggle to making progress with entrepreneurial or innovation developments amidst a host of priorities including daily coursework demands, student/community service, and other activities that compete for their limited time.

At the heart of the issue then is "how do we help students develop these skills - to be more effective in their careers whether intrapreneurial or entrepreneurial"? Our journey to address this question began more than ten years ago and has led to the development and implementation of many initiatives to create a culture of innovation and development of a cohesive I\&E ecosystem surrounded by a robust resource network.

\section{Founding I\&E Programs}

Experienced-Based Learning in an Entrepreneurial Setting - In 2000, Michigan Tech launched an innovative undergraduate curriculum, The Enterprise Program. Initially funded as an NSF Action Agenda pilot program (EEC-9872533), Enterprise is an extensive multi-year, multidisciplinary design experience and is offered as an alternative to senior capstone design. All participants complete an Enterprise curriculum which includes a minimum of 12 credits. Students join specific "enterprises" which are structured within the University as engineering/business entities that operate as much as possible like a real company in the private sector. Enterprises consist of multi-disciplinary, multi-year teams ranging in size from 10 to 70 or more students with conventional organizational charts including a distribution of management and technical responsibilities spread across functions including team leadership, project execution/implementation, talent recruitment, and new business/product development. Team members innovate solutions, perform testing and analyses, make recommendations, manufacture parts, stay within budgets and schedules, and manage multiple projects. Faculty members and industry sponsors serve as advisors and mentors. Toward the end of spring semester each year, Enterprise teams submit detailed written reports that include results of their projects. The teams also make oral presentations to faculty and students, industry mentors and sponsors, and the public. 
The Enterprise teams offer students, from varied disciplines, the opportunity to work for several years in a business-like setting to solve real-world problems. These problems and the associated project opportunities are often supplied to the teams by industry sponsors, however new product ideas also come from within the team. These internal projects are selected based on team member interests, strengths, and market potential.

The Enterprise Program was recently highlighted in NAE's publication "Infusing Real World Experience into Engineering Education" as one of 29 exemplar programs nationwide that successfully integrate real-world experience into the undergraduate engineering curriculum. With the Enterprise program, the College of Engineering liberated some of the assigned technical/approved electives and created a new and different experience designed to educate and prepare graduating engineers for more productive and successful careers. ${ }^{8}$ Annual participation has grown from 230 students and 11 Enterprise teams in its initial year (2000) to over 800 students on 27 different Enterprise teams. These teams include participants from from at least 19 different engineering, business, and sciences \& arts disciplines who work in a truly crossfunctional manner. Each year, through the efforts of program staff and team members, more than $\$ 500,000$ in industry funding is recruited to sustain and grow the Enterprise program.

The Enterprise curriculum and training experience, by careful design, offers opportunities for students to acquire and improve all professional attributes - beyond technical competencies - that have been identified as essential to educating the engineers of 2020: strong analytical skills, practical ingenuity, creativity, solid communication skills, knowledge of business and management principles, leadership skills, high ethical and professional standards, flexibility, and lifelong learners. ${ }^{4}$ By all definitions discussed in the NAE Phase I Report, the Enterprise curriculum and experience is engaging, relevant, and welcoming, the three areas in which engineering education must justifiably direct considerable attention. ${ }^{4}$ The Enterprise model, by design and in practice, requires a high degree of interaction among team members and between student team members and faculty advisors and industry mentors. Research establishes that these interactions are the most predictive measures of positive change in college students' academic and personal development and satisfaction. ${ }^{1}$ The Enterprise program, as a core imperative for educating engineers for the future, teaches and trains students for professional practice - with practice understood as the "complex, creative, responsible, contextually grounded activities that define the work of engineers at its best". 7

The program, with its emphasis on communication, leadership and teamwork skills, creative problem-solving, and a better understanding of business and financial management, is geared toward developing an entrepreneurial mindset. ${ }^{2}$ There are a number of indications that the Enterprise program has been successful in the general objective of developing this mindset within the students, such as the percentage of undergraduate patent disclosures. Since the introduction of the Enterprise Program, there has been an additional expectation that, from this innovative educational experience, new products and technologies would be commercialized and new businesses would emerge. While commercialization and new business creation is not a specific metric by which success of the program is measured, it is, nonetheless, a desired outcome of the program and an indicator of the full development and realization of applied innovation skills among program graduates. Despite an increase in the level of entrepreneurial 
interest, innovation skills, and preliminary outcomes such as patent disclosures demonstrated by Enterprise students, there has been little translation of this into the desired activity level in direct entrepreneurial endeavors (successful startup businesses and new products in the marketplace).

As evidence of the program's success, employers actively pursue Enterprise students and those students have proven very successful in translating their skills into significant value for their employers. However, beyond the professional success of the students in contributing substantial business, technical, and leadership value to their employers and the internal adoption by sponsors of team-developed solutions, there have been limited outcomes to-date in generating independent entrepreneurial outcomes including commercialization of Enterprise-developed technologies or products into commercially offered products or the formation of new businesses.

Regional Business Incubators - Also, in 2000, Michigan Tech, in partnership with the cities of Houghton and Hancock and Keweenaw Industrial Council (now the Keweenaw Economic Development Alliance) led the development of a proposal to establish a local business incubator/accelerator under a newly formed a state program entitled "SmartZones". Under the SmartZone program, and through local tax capture provided under the enabling legislation, the State supported acceleration of innovation at regional hubs and facilitated increased connections between universities and regional entrepreneurs and innovators. The area was awarded the first of three regionally focused business incubation and acceleration programs and a new non-profit private entity, the Michigan Tech Enterprise Corporation (MTEC) SmartZone was formed. MTEC is a private entity that independently serves the regional community but was managed by one of the authors under contract to the University for its first three years of operation, prior to recruitment of permanent and independent staff. Michigan now has 15 designated SmartZones and the program has become widely recognized as successful in facilitating startup and growth of technology companies.

Creation of MTEC and increased collaboration with regional economic development partners was a founding cornerstone of the nascent regional I\&E Ecosystem. MTEC in particular became a focal point to serve community-based entrepreneurs and innovators. It gave them a place to go to begin to connect with others in the community, including University faculty, staff, and students with complementary interests. While the program has been successful in advancing and accelerating historical successes related to regional technology company development, connections to student-based innovation and entrepreneurial interests, and programs directed at serving interested students have been variable over time resulting in loss of momentum during peaks and valleys of activity. This variability, compounded by the turnover as students graduate and move on to pursue either their entrepreneurial or intrapreneurial interests outside of the local area, resulted in the need for campus-based and student-focused programs that complement community programs but maintain momentum and focus on student needs and perspectives.

Business and Design Competitions - Business plan competitions are sometimes solely thought of as mechanisms for students to get early stage funding for their entrepreneurial endeavors. More importantly, they also provide a range of other core benefits including entrepreneurial skill development, engagement with mentors and professional networks, increased self-confidence, and reduced risk aversion ${ }^{9}$. In addition to full-scale business plan competitions; pitch events and design expositions also offer similar experiences, educational value, and professional networking 
opportunities. Under the Enterprise Program as well as departmental senior capstone activities, all students have an opportunity to present their work and to compete for prizes at the annual campus Design Expo (http://blogs.mtu.edu/expo/). For students interested in specific entrepreneurial endeavors including startup companies as well as licensable technology development activities, our University has conducted an annual elevator pitch competition on campus and has participated in a series of regional and national competitions including a partnership with Central Michigan University in their annual New Venture Competition and the annual statewide Accelerate Michigan Business Competition.

Participation in these programs has provided students with valuable learning and networking opportunities. In some cases funding received from participating in these competitions has enabled student-led companies to move forward into the market with products and/or proceed with private fundraising (e.g. http://www.baisikeliugunduzi.com and http://www.uplandnanotech.com/). The support infrastructure for students participating in these competitions has largely been through volunteer and ad-hoc efforts among a small group of passionate stakeholders. As such, the available support effort and integration of support resources has varied over time leading to variation in the number of teams participating and the successes achieved by those teams. For example the number of participating teams in the CMU New Venture Competition has ranged from 0 to 7 from year to year. In high participation (and robustly supported) years, teams have been awarded as much as $\$ 45,000$ in total and in low participation (and unsupported) years, teams have either not competed or not been successful either in winning prize funding or moving forward to formal company establishment.

Technology Transfer Office - Michigan Tech established a formal Technology Transfer Office (TTO) in 1983 and has been actively involved in startup business development even before formal establishment. Beyond conventional and core technology assessment, proprietary protection, and licensing activities; the TTO has historically taken a hands-on and direct support role within many of the companies it creates. This role includes acting as, or in some cases becoming, the founding team. Activities within this role range from strategic and tactical planning to fundraising through angel and venture capital as well as grants, such as SBIR and STTR to cultivation of prospective customers and strategic partners. The primary focus for this activity is on University-owned technologies whereas most student-led companies are working to commercialize technologies outside the scope of University ownership. Nonetheless, since 2000 TTO staff have made themselves available to support students as their other workload permits. Support has included an annual 1-credit offering in Technology Commercialization and a 3credit offering in Fundamentals of Intellectual Property Law taught by TTO staff in an overload capacity as well as on-demand counseling for student-led companies, often focused around competition participation.

This activity has provided access by students to an applied experience base and a relatively robust network of entrepreneurial resources but, similar to the competition and regional incubator support activities has largely been ad-hoc and volunteer, and only available as time and competing priorities permit.

Founding Activity Summary - The establishment and success of the Enterprise Program within the curriculum complemented by other emerging resources and programs including the 
SmartZone, Design and Business Competitions, and access to Technology Transfer Office staff enabled the construction of a basic foundation for an I\&E Ecosystem. While these activities were individually valuable and somewhat coordinated, they lacked a deliberate student-directed focus and were subject to variable availability based on competing priorities and workload associated among individuals serving in largely a volunteer or overload capacity.

\section{Benchmarking Activities}

We identified early on that a different approach was needed if we were to ever realize the goal of a sustained pipeline of new products in the marketplace and student start-ups arising from Enterprise or other student-based entrepreneurial and innovation activities. Beginning in 2005, the authors embarked on a benchmarking and information gathering mission to identify best practices in entrepreneurial education at that time. Visits to schools/programs such as Johns Hopkins W.P. Carey Program in Entrepreneurship and Management, Rowan's Center for Innovation and Entrepreneurship, the University of Maryland's Hinman CEOs Program, the University of Michigan Zell Lurie Institute for Entrepreneurial Studies, and others led to the creation of a white paper which was presented to university administration proposing a plan to strengthen the undergraduate entrepreneurial curriculum and bridge the gap from an encouraging level of activity to an increased level of outcomes.

Conclusions from the benchmarking activities and core elements of the white paper included:

- Operating a cohesive program outside of any specific college or school has advantages in reducing perceived barriers to collaboration and coordination.

- A robust and connected innovation and entrepreneurship curriculum is necessary to elevate formal understanding of core fundamentals.

- Discrete educational programs such as minors provide actionable opportunities for students to pursue and obtain identifiable credential in their transcripts.

- Funding, particularly in the form of endowed support for staff and faculty provides sustainable 'glue' to hold programmatic elements together and reduce the reliance on volunteer/overload support activities.

- Events with either a social (e.g. meetups) or programmatic component (e.g. boot camps) provide opportunities for introducing prospective entrepreneurs to the fundamentals and building enthusiasm.

- IP policies are perceived as significant and need to be characterized as non-threatening to students' entrepreneurial desires.

- Students are highly receptive to instruction and mentorship from practitioners through adjunct appointments.

- Diligent and early idea screening is fundamental to development of solid student concepts. Students should be encouraged to be constructively critical of each other to drive sound concepts with market potential.

- Staging development from idea validation to model validation to business execution provides for a 'bite-sized' path from concept to customer that works well for students who have many competing priorities for their time and effort.

Interestingly, we find that these same conclusions are still relevant today, and are representative of the core elements we still believe are needed on our campus in order to effect positive change. 
Unfortunately, limited resources available for new program development at the time we initially presented these findings, and working within an arguably successful status quo, resulted in the proposed plan not being supported. Following this, the authors returned to their daily roles and continued to try to advance entrepreneurial activity in limited ways that aligned with their core responsibilities or that could be sustained through their individual passion and personal decisions to take on overload commitments. This approach allowed for only a minimal level of continued engagement in activities which could incrementally build programs, advance the culture, and support development of a robust I\&E ecosystem.

During the ten years that the team bootstrapped activities and initiatives, national and regional models of innovation and entrepreneurship support were emerging that ultimately brought rise to highly impactful initiatives including the NSF's Innovation Corps (I-Corps) program and its use of the Lean Start-up curriculum developed by Steve Blank, the Pathways to Innovation and University Innovation Fellows programs, offered by Stanford's Epicenter program, as well as the growth and programmatic maturity of regional and national pitch and business plan competitions. In parallel with the establishment of robust national and regional programs, a groundswell of interest from entrepreneurial alumni with interests in supporting I\&E development began to emerge. Our mission to go beyond incremental bootstrapped activities to infuse innovation and entrepreneurship across campus was renewed and finally made actionable.

\section{Emergence of Integrating Programs to Bridge Gaps in the I\&E Ecosystem}

NSF I-Corps Program - To-date, Michigan Tech has fielded five teams through NSF's National I-Corps Program. Two of those teams earned top "Teaching Team" honors for their respective cohorts, and multiple teams have gone on to receive STTR funding. We are proud of the accomplishments of these teams and have become firm believers in the benefits of applying the Lean Start-up methodology to assess the viability of opportunities and chart a path toward execution. Both authors participated as mentors to various I-Corps teams which led to positive first-hand experiences with the curriculum and a realization that the robust yet digestible structure provided within the Lean Start-up method is exactly what we needed to address the educational gaps in entrepreneurship education. We attended the Lean Start-up faculty workshop in 2013 with the intent of bringing the curriculum back to our campus in a meaningful way. This further led to funding as an NSF I-Corps Site, providing necessary resources to infuse the Lean Start-up curriculum across campus. Since the I-Corps Site award in early 2015, over 60 undergraduate and graduate students, faculty and staff have been formally introduced to the Lean Start-up and Business Model Canvas methodologies through courses and workshops. Participants in these courses and workshops have expressed realization of value related to both identification of viable business models and execution paths and invalidation of hypothetically attractive business models which were proven infeasible for various reasons as illuminated by the thoughtful and deliberate analysis facilitated through the Lean Start-up method.

Pathways to Innovation and University Innovation Fellows Programs - Shortly after engaging with the NSF I-Corps program, we also learned about Stanford's NSF funded Epicenter program and its Pathways to Innovation and University Innovation Fellows programs. We were fortunate to be accepted to the pilot cohort of Pathways in 2014, and formed an interdisciplinary team of faculty to participate in the Pathways workshops. This provided a significant opportunity to 
engage faculty who shared our vision to infuse innovation and entrepreneurship throughout our campus in a meaningful way but who lacked context or experience regarding how to directly integrate it into their ongoing efforts. Pathways provided access to much needed training and support resources and jump-started our efforts to advance our vision and expand the team of committed grass-roots supporters.

In addition to the faculty support offered through Pathways, we also engaged in the highly successful University Innovation Fellows (UIF) program, also through the Epicenter program. Similar to Pathways, UIF engages students in the I\&E mission through training and support resources, enabling them to be change agents on their campus. To date, we have ten students who have successfully completed the UIF program and are actively involved in the process of building a strong I\&E culture through student-led initiatives. This student activity has probably had the biggest impact in creating a movement among the students and facilitating positive change. In fact, our UIF students have created a new student organization called The Movement, whose mission is to build awareness and excitement around creativity and innovation across campus.

Integrating Program Summary - Emergence of the I-Corps program including individual team training opportunities under the National Science Foundation program and educator training opportunities offered by VentureWell (formerly NCIIA) served as a critical and timely "glue" to motivate and provide for participation of entrepreneurial minded teams in a robust and consistent process. National and regional I-Corps cohorts have primarily included faculty, staff, and graduate students expanding the knowledge base across campus among long-term stakeholders. In addition, the recent establishment of our university as an NSF I-Corps Site has provided a significant opportunity to engage undergraduate students in an identical process allowing all stakeholders from students, faculty and staff, to regional service providers and mentors to speak a common language and identify with a model process that is very actionable, digestible, and outcome oriented.

In addition to the cohesion enabled by a consistent business model development approach under I-Corps/Lean Launchpad, participation by undergraduate students in the University Innovation Fellows program has resulted in a grass-roots groundswell within the student body. The UIF students who have been trained in leadership and fundamentals of design-thinking are perfectly suited to advance the culture from the 'bottom up' and motivate change and program development across the institution and community. Similarly, participation in the Pathways to Innovation program has provided a venue to bring a broad coalition of faculty into the I\&E Ecosystem. In particular, faculty involved in the Pathways effort include those with a passion for innovation and entrepreneurship education but who may not have a direct interest in building a startup company, and therefore are not targets for I-Corps and associated training programs.

As a result of I-Corps, UIF, and Pathways participation we have realized a highly connected network of stakeholders with complementary interests related both to starting new companies and advancing educational and experiential opportunities across campus. This evolution presents a substantial opportunity to move forward from a functional but disconnected and inefficient I\&E Ecosystem to one that is much more effective at generating outcomes in a natural and sustained manner. 


\section{Connecting all of the Dots - Development of a Fully Connected I\&E Ecosystem}

The I-Corps, Pathways and UIF opportunities came at a critical time in Michigan Tech's strategic development. A "perfect storm" of administration recognition of the need for a strong I\&E ecosystem, alumni demand for action, and the aforementioned faculty and student training opportunities have finally allowed for significant advancement toward achieving the mission begun over ten years ago. A significant advancement in strengthening and connecting all of the elements of our I\&E Ecosystem is the newly created Innovation Center for Entrepreneurship. With support from the administrative team and as a result of identified program needs and donor interest, the Innovation Center for Entrepreneurship was launched in Fall 2015. The Center was formalized within the cross-disciplinary Pavlis Honors College which has provided a 'home' for the activity that explicitly cuts across individual academic units and programs. The Vision of the Center is to facilitate a University campus where entrepreneurial mindset thrives throughout the community and across disciplines, converting ideas into capital. The Mission of the Center is to harness the potential of the campus community to innovate, develop, and implement ideas and inventions by building and maintaining a strong and integrated ecosystem with a cohesive set of innovation and entrepreneurial resources to enable success.

Notably, the Center is not intended to overlap or replicate activities already existing on campus and in the community. Rather the Center is intended to 'connect the dots' between existing activities, build bridges between those dots as necessary, and address any gaps identified in the ecosystem. While the practical and literal definitions of the terms "Innovation" and "Entrepreneurship" vary by context and field, with respect to the Center Programs, Innovation primarily relates to the creation of meaningful opportunities with actionable commercial outcomes whereas Entrepreneurship refers to executing on those opportunities in fulfillment of commercial outcomes. There is extensive overlap across the continuum from creation/discovery to execution and outcome. Center programs and lead personnel assignments are being designed to focus on areas of the continuum most appropriate for the stage of the opportunity, the individuals involved, the technology being pursued, and other relevant factors. This I\&E continuum, as we envision it, is reflected in Figure 1.

Key initiatives of the Center include creation of an Innovators \& Entrepreneurs guest speaker series, execution of a coordinated pitch competition strategy, development of a mentor network, enhanced curricular programming, and a thorough ecosystem resource mapping effort. All of this will be done in close collaboration with a recently established stakeholder group that includes representatives from a host of campus and community-based programs including individual faculty and college deans, the local SmartZone business incubator, the Technology Transfer Office, and relevant student groups. 
Figure 1. I\&E Continuum

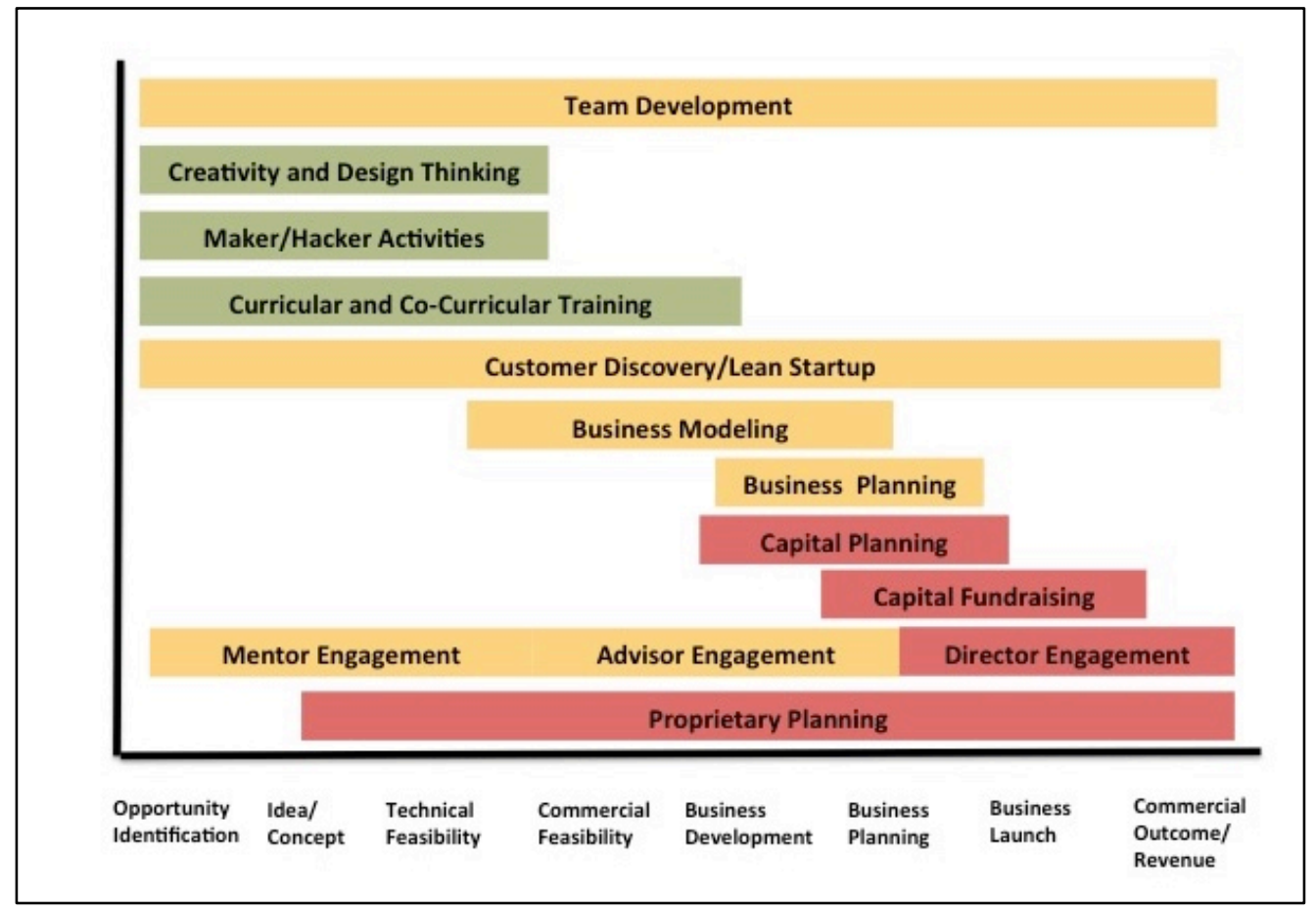

Another key initiative is the development of a Maker Space. While many student/faculty project and shop spaces exist across campus, access is limited to specific classes and research projects, and require a complex system of training, essentially making these spaces inaccessible to a majority of campus. The university has recently allocated the use of $4000 \mathrm{sq} \mathrm{ft}$ (previously a bowling alley) in the centrally located student union building, to be renovated and re-purposed as a campus-wide Maker Space. This space is intended to be accessible to faculty, staff and students from all disciplines across campus, to provide low-resolution prototyping capability and collaboration space. Modeled after successful makerspaces at MIT and Georgia Tech, we believe this space will fill a critical gap in our I\&E ecosystem. With a mix of hand and power tools, 3D printers, laser-cutters, modeling stations and collaborative workspaces, our Innovation Alley will allow people to come together to create, design and build, bringing their ideas to life. The Alley is currently under development and is expected to be operational by early Fall 2016.

As previously mentioned, Michigan Tech was awarded an NSF I-Corps Site grant in 2015. Through this grant, we are rigorously applying the I-Corps philosophy and Lean Start-up practices to strengthen our efforts to support entrepreneurial initiatives and to better bridge the gap on the technology development continuum where innovation commonly stalls or is abandoned. Common reasons for this gap include disconnects between technical trajectory and ultimate customer needs, insufficient skills among innovation team members, and lack of resources, champions, mentors, and advisors. The Lean Start-up methodology is specifically designed to minimize these threats to promising innovations. By introducing Lean Start-up methodology widely across campus, we anticipate increased start-up business development and other commercialization initiatives, an increased rate of success of those initiatives, and improved knowledge and skill development that will be used, shared, and perpetuated by all 
participants. Table I provides a summary of key activities and initiatives surrounding development of our I\&E Ecosystem.

\begin{tabular}{|c|}
\hline $\begin{aligned} \text { Table 1. Timeline of the Evolution of the I\&E Ecosystem } \\
\text { Discovery }(2000-2005)\end{aligned}$ \\
\hline $\begin{array}{l}\text { Assess commercial outcomes from Enterprise, Capstone and other Student Activities } \\
\text { Limited realization of independent product commercialization or new business formation. }\end{array}$ \\
\hline Planning (2005) \\
\hline Benchmarking - Exploring models of success and lessons learned from others. \\
\hline $\begin{array}{l}\text { White Paper Development - Compilation of the collection of best practices against the current } \\
\text { state and desired future of the I\&E Ecosystem }\end{array}$ \\
\hline Bootstrapping (2005-2011) \\
\hline $\begin{array}{l}\text { Curricular Development - Piloted UG Technology Commercialization course delivered by } \\
\text { technology transfer personnel in collaboration with Enterprise Program personnel. }\end{array}$ \\
\hline $\begin{array}{l}\text { Individual student engagement and team support - Connected with individual students to build } \\
\text { enthusiasm and support teams in business pitch/plan competitions }\end{array}$ \\
\hline $\begin{array}{l}\text { I\&E Network Development - Cultivated connections with key partner/support organizations such } \\
\text { as NCIIA (now VentureWell) }\end{array}$ \\
\hline Program Building (2011-2015) \\
\hline National I-Corps Teams - Increased awareness of fundamentals within campus community \\
\hline Pathways to Innovation - Engage key academic leadership to facilitate infusion of I\&E initiatives \\
\hline University Innovation Fellows - Enthusiastic students trained to be agents of cultural change \\
\hline $\begin{array}{l}\text { Local I-Corps Program and Lean Launchpad Curriculum Training - Formal training of University } \\
\text { personnel and execution of Lean Launchpad courses }\end{array}$ \\
\hline I-Corps Site Program - Increase offering of Lean Launchpad methodology \\
\hline Alumni Cultivation - Outreach to individuals interested in financial and intellectual support \\
\hline Honors College - Cross-disciplinary "home" for experiential learning opportunities \\
\hline Competition Engagement - Expanded support for students in pitch competitions \\
\hline $\begin{array}{l}\text { Cross-Campus and Regional Resource Cooperation - Active dialogue about how individual } \\
\text { activities can complement one another }\end{array}$ \\
\hline Center Launch (2015-2016) \\
\hline Designated Personnel - Shift from overload duty to designated duty at a part-time level \\
\hline Speaker, Event, and Workshop Series - Build continuity of speakers, events and workshops \\
\hline $\begin{array}{l}\text { Curricular Expansion - Integrate creativity, design, business model, and execution fundamentals } \\
\text { in new and existing courses }\end{array}$ \\
\hline Alumni/Partner Engagement - Financial support plus engagement with programs/students \\
\hline Stakeholder Group - Facilitate engagement of leaders from across campus and the region \\
\hline $\begin{array}{l}\text { Competition Support - Deliberate support for student teams in business plan and pitch } \\
\text { competitions and engagement with strategic partners, funders, and others. }\end{array}$ \\
\hline $\begin{array}{l}\text { Cross-Campus and Regional Collaboration - Active dialogue to facilitate collaboration and } \\
\text { identification and engagement of regional partners }\end{array}$ \\
\hline Center Expansion (2016 ->) \\
\hline Dedicated Personnel - Full time center leadership \\
\hline Mentor(s)-in-Residence - On-campus practitioners actively working with students \\
\hline $\begin{array}{l}\text { Curricular Integration - Cohesive connections across multiple existing and new curricular } \\
\text { offerings and creation of an I\&E Minor }\end{array}$ \\
\hline $\begin{array}{l}\text { Regional Resource Integration - Transition from campus-based support programs and resources } \\
\text { to public/private (incubators/business development consultants, etc). }\end{array}$ \\
\hline
\end{tabular}




\section{Assessment}

Throughout the journey and looking into the future, regular assessment has been a core consideration of the team. These assessments have, and will continue to provide insight into the status of the I\&E Ecosystem as a whole, particularly in terms of what is working, what is not, and where opportunities lie within elements of the I\&E Ecosystem.

Near term assessment instruments include course evaluations from for-credit offerings and surveys conducted for each I-Corps cohort (4 completed to-date). Course evaluations assess student's perspectives of course content and structure as well as, delivery mechanisms such as use of a flipped classroom. I-Corps surveys seek feedback regarding entrepreneurial interests and aptitude before and after the program and also seek feedback regarding content, structure, and format.

Middle-term assessment metrics include: enrollment in I\&E courses, number of courses incorporating I\&E fundamentals, enrollment in I-Corps cohorts, attendance at I\&E workshops and events, quality and volume of invention disclosures to the University technology transfer office, numbers of engaged faculty and mentors, and participation in business model pitch competitions.

Longitudinal assessment metrics include: startup companies launched, products in development, follow-on funding raised by startups, products in the commercial marketplace and entrepreneurial/intrapreneurial successes of students post-graduation.

Assessment of individual and historical components of the I\&E Ecosystem have been conducted previously as part of the business of the involved stakeholders and focused on their individual metrics. As the Center moves forward it is actively working on integrating those existing assessment activities complemented with additional activities and metrics identified during the ongoing ecosystem mapping exercise conducted with the aforementioned stakeholder group.

\section{Conclusions and Lessons Learned}

After a decade of persisting on this journey, we are well on our way to achieving the Innovation \& Entrepreneurship Ecosystem we envisioned in 2005, and it has only been possible with a great deal of help from a knowledgeable network of those who have made this journey before us. To paraphrase Isaac Newton, "if we have seen further it is by standing on the shoulders of giants". The community of innovators, makers, and entrepreneurs from the many universities and organizations we have connected with over the years, has been incredibly supportive, and there have been many lessons learned along the way which we hope to share with those who might be in the early stages of their own journey:

1. Engage students early in the process - students are a powerhouse of ideas, enthusiasm and energy and the number of students who want to engage in this process to bring about culture change in greater than we imagined. Find them, engage them in the process and help them to bring their ideas to light. 
2. Partner with existing university/community resources - most universities, like ours, have a number of resources already in place, and people who are already engaged in work that falls somewhere along the continuum of innovation and entrepreneurship. Whether it's the local business incubators, the community's business development activity, staff from the Technology Transfer office, or faculty who are building businesses or teaching elements of I\&E in their classes...bring them all into the process. There is no need to start from scratch.

3. Enlist the help of alumni - we are fortunate to have a very engaged alumni base, many of whom have practical experience in innovation, start-ups, investor development and other related areas of the I\&E Ecosystem. While not all can provide funding, most are eager and willing to lend their time and expertise by engaging as mentors, guest speakers, pitch competition judges and advisors.

4. Borrow great ideas - the process of benchmarking has helped us to identify many great programs and resources that others have implemented. There is no need to re-invent the wheel. Without exception, everyone we have reached out to over the years has been willing to help in some way. The community of people engaged in building I\&E culture is a passionate one, and in our experience, all are happy to share their time, wisdom, and expertise, and lessons learned.

5. Patience and persistence - organizational change, especially in academic settings, takes time. Staying the course, building a network of individuals who are passionate about the cause, and working from a grass roots level, does lead to results. It just takes persistence and a great deal of patience.

6. Supportive IP Policies - Clarify the scope of University IP policies to apply to activities directly sponsored by third parties or by the University in the form of payroll or access to specialized facilities that are not generally available to students except within the access provided through course enrollment. All activities outside these constraints should be considered outside the scope of University IP.

7. Use data to support your case - there is a strong community of researchers working in the I\&E space who are generating a lot of useful data that can help strengthen your case when presenting your vision to key stakeholders. Data is available for everything from statistics on the value of makerspaces to the impact on key metrics from I\&E courses, and the research community has been very willing to help us find, or generate, the data needed to support our case.

\section{Bibliography}

1. Astin, Alexander W. What matters in college?: Four critical years revisited. Vol. 1. San Francisco: JosseyBass, 1993.

2. Bilen, S. G., et al. "April 2005,"Developing and assessing students' entrepreneurial skills and mind-set,"." Journal of Engineering Education 94.2: 233-243.

3. Byers, T., et al. "Entrepreneurship: Its role in engineering education." The Bridge 43.2 (2013): 35-40.

4. Jamieson, Leah H., and Jack R. Lohmann. "Creating a Culture for Scholarly and Systematic Innovation in Engineering Education: Ensuring US engineering has the right people with the right talent for a global society." Washington, DC: American Society for Engineering Education (2009).

5. National Academy of Engineering. Educating the Engineer of 2020: Adapting Engineering to the New Century. National Academies Press. 2005. 
6. Pryor JH, Hurtado S, DeAngelo L, Blake LP, Tran S. The American freshman: National norms fall 2010. Higher Education Research Institute, 2010.

7. Shepard, Sheri, Macatangay, Kelly, Colby, Ann, Sullivan, William. Educating Engineers: Designing for the Future of the Field. The Carnegie Foundation for the Advancement of Teaching: Preparation for the Professions. Jossey-Bass. 2009.

8. Sorby, S. \& Raber, M. (2005, September). Learning Across Boundaries through the Enterprise Program. 4th Global Colloquium on Engineering Education, Sydney, Australia.

9. Russell, Roslyn; Atchison, Mary; Brooks, Robert (2008, May) Business Plan Competitions in Tertiary Institutions: Encouraging Entrepreneurship Education Journal of Higher Education Policy and Management, v30 n2 p123-138. 